\title{
Os conflitos pelo Direito à Cidade em Fortaleza: disputas entre a visão estratégica da cidade e a regulamentação das ZEIS
}

\author{
Conflicts over the Right to the City in Fortaleza: disputes \\ between the city's strategic vision and the regulation of ZEIS
}

Amíria Bezerra Brasil [a] [D

[a] Universidade Federal do Rio Grande do Norte (UFRN), Natal, RN, Brasil

Como citar: Brasil, A. B. (2021). Os conflitos pelo Direito à Cidade em Fortaleza: disputas entre a visão estratégica da cidade e a regulamentação das ZEIS. urbe. Revista Brasileira de Gestão Urbana, v. 13, e20200341.

https://doi.org/10.1590/2175-3369.013.e20200341

\section{Resumo}

Desde o início do século XX a produção do espaço urbano em Fortaleza seguiu lógica protagonizada pelos setores privados, pouco regulada pelo Estado, ratificada pelos investimentos públicos consolidando-se um espaço desigual. Somente após a aprovação da Constituição Federal e do Estatuto da Cidade foram inseridos instrumentos urbanísticos nos Planos Diretores que seriam capazes de reverter essa lógica, destacando-se as ZEIS. Entretanto, eles não foram implementados, ou o foram a partir de uma lógica às avessas que favoreceu a produção mercantilista da cidade. Os assentamentos informais permanecem sob o risco de remoção, a produção de novas habitações sociais continua de forma periférica, e os investimentos públicos favorecem a valorização da terra em localizações específicas. 0 objetivo desse artigo é, portanto, discutir a preponderância da lógica mercantilista de produção do espaço em Fortaleza em detrimento da garantia do Direito à Cidade, apesar da delimitação das ZEIS no PDPFor (2009). 0 artigo é um dos resultados da tese de doutorado, que foi desenvolvida a partir de entrevistas com os agentes envolvidos, consultas aos documentos da Prefeitura e referências bibliográficas destacadas ao longo do texto.

Palavras-chave: Direito à cidade. Produção desigual do espaço. ZEIS. Fortaleza.

\section{Abstract}

Since the beginning of the 20th century, the production of urban space in Fortaleza has followed a logic led by the private sectors, barely regulated by the State, ratified by public investments, consolidating an uneven space. Only after the approval of the Federal Constitution and the City Statute were urban instruments introduced in the Master Plans to reverse that logic, especially the ZEIS. However, either they were not implemented, or, if so, were based on an upside-down logic that favored the city's mercantilist production. Informal settlements remain at risk of eviction, the production of new social housing continues on a peripheral basis, and public investments favor the valorization of land in specific locations. The objective of this article is, therefore, to discuss the preponderance of the mercantilist logic of space production in Fortaleza to the detriment of guaranteeing the 
Right to the City, even despite the delimitation of the ZEIS in PDPFor (2009). The article is one of the results of the doctoral thesis, which was developed from interviews with the agents involved, consultations of the documents at the City Hall and bibliographical references highlighted throughout the text.

Keywords: Right to the City. Uneven production of space. ZEIS. Fortaleza.

\section{Introdução}

A produção do espaço urbano em Fortaleza, Ceará, durante o século XX e início do século XXI, se deu marcada por intensa desigualdade socioespacial, protagonizada pela iniciativa privada e com insuficiente regulação estatal. Esse fato, aliado à intensa valorização da terra, fez com que fossem consolidados muitos assentamentos informais, que buscavam atender à demanda habitacional da população que não podia pagar pela produção privada da moradia, nem acessar a terra urbana, mercadoria de alto valor. Assim, formaramse diversas favelas, loteamentos irregulares, cortiços e outras formas de promoção da habitação. Esses assentamentos, de origem informal, estão distribuídos por todo o território municipal de forma não homogênea, localizados em especial em áreas de fragilidade ambiental, e concentrados nas porções oeste e noroeste.

O planejamento urbano, através da legislação de ordenamento territorial, não foi capaz de rever essa lógica mercantilista e desigual de produção do espaço. Somente em fins do século XX, após a aprovação da Constituição Federal de 1988, os primeiros instrumentos urbanísticos que poderiam promover uma distribuição mais igualitária do espaço urbano e da mais-valia urbana foram previstos no Plano Diretor de 1992.

Esse plano começou a ser revisto em 2003, após a aprovação do Estatuto da Cidade, em 2001, e a revisão foi finalizada em 2009, em um processo bastante conturbado. O Plano Diretor Participativo de Fortaleza (PDPFor) incorporou diversos instrumentos urbanísticos, dentre eles as Zonas Especiais de Interesse Social (ZEIS), que deveriam contribuir com a efetivação do Direito à Cidade e do cumprimento da Função Social da Propriedade. Definidas em três tipos diferentes, as ZEIS poderiam colaborar para reverter a lógica de produção desigual do espaço urbano, garantindo e regulamentando moradia digna às famílias de baixa renda.

Entretanto, esse instrumento não foi regulamentado até hoje ${ }^{1}$ devido a diversos entraves em seu processo. Os assentamentos localizados em áreas estratégicas da cidade, que disputam espaço com interesses dos setores imobiliário e turístico, continuam ameaçados de remoção total ou parcial, já tendo partes deles, inclusive, sido relocadas. Os conflitos se dão devido à disputa entre a visão estratégica de cidade (Vainer, 2007), a cidade como negócio (Harvey, 1996), e o Direto à Cidade ${ }^{2}$ (Lefebvre, 2004), garantido pela Constituição Federal (1988) e reforçado pelo Estatuto da Cidade (2001) e pelo PDPFor (2009). Essas disputas, os entraves e os conflitos, no contexto do processo de revisão e aprovação do PDPFor (2009) serão apresentados nesse artigo, que busca discutir o processo de regulamentação das ZEIS, em especial o tipo 1 - assentamentos consolidados - com o recorte temporal até o ano de $2016^{3}$. 0 artigo está dividido em 4 partes, iniciando-se por uma discussão conceitual sobre Direito à Cidade e Função Social da Propriedade, e seu rebatimento na legislação de Fortaleza. Após, será abordada a formação da desigualdade socioespacial em Fortaleza, seguida da discussão acerca dos instrumentos urbanísticos incorporados no

\footnotetext{
${ }^{1}$ Considera-se o ano de escrita deste artigo, 2020.

20 Direito à Cidade é entendido neste artigo dentro dos limites do que estabelece a legislação brasileira, porém considerando, também, como foi tratado na tese de doutorado que deu origem a este artigo, o que estabelece Henry Lefebvre, em sua obra 0 Direito à Cidade (2004), originalmente publicada em 1968. 0 termo é tratado também por David Harvey em publicações recentes (Harvey, 2013).

${ }^{3} \mathrm{~A}$ tese de doutorado é intitulada "A ineficácia das ZEIS: um problema de legislação ou uma questão político-social? - 0 caso de Fortaleza “, desenvolvida sob orientação do prof. Dr. João Sette Whitaker Ferreira, com financiamento da Coordenação de Aperfeiçoamento de Pessoal de Nível Superior (CAPES) e foi defendida em 2016.
} 
PDPFor, em especial as ZEIS, cuja discussão finalizará o artigo a partir da reflexão acerca da sua [não] regulamentação e os conflitos que permeiam esse tema.

\section{Direito à Cidade e Função Social da Propriedade na legislação de Fortaleza}

As discussões acerca do direito à cidade e da função social da propriedade foram incorporadas na legislação brasileira a partir da Constituição Federal (1988), mas especialmente com a aprovação do Estatuto da Cidade (2001), e foram rebatidas nos planos diretores aprovados ou revistos após esses marcos regulatórios.

0 direito à cidade não está claramente definido na legislação brasileira, sendo então relacionado ao direito à moradia e ao acesso aos serviços públicos básicos. 0 conceito, entretanto, tratado por Henri Lefebvre, em seu livro com este nome, vai além, trata em uma perspectiva de revolução sob a hegemonia da classe operária, a prevalência do valor de uso ao valor de troca na cidade (Lefebvre, 2004). David Harvey, a partir de Lefebvre, trata o direito à cidade também de forma mais ampla, para ele a reinvindicação do direito à cidade se dá a partir de um "maior controle democrático sobre a produção e o uso do excedente" (Harvey, 2014, p. 61) no processo de urbanização, ou ainda "é um direito de mudar e reinventar a cidade mais de acordo com nossos mais profundos desejos” (Harvey, 2014, p. 28).

A função social da propriedade, entretanto, está definida no Estatuto da Cidade, mas passa para os municípios a responsabilidade de detalhá-lo:

Art. 39. A propriedade urbana cumpre sua função social quando atende às exigências fundamentais de ordenação da cidade expressas no plano diretor, assegurando o atendimento das necessidades dos cidadãos quanto à qualidade de vida, à justiça social e ao desenvolvimento das atividades econômicas, respeitadas as diretrizes previstas no art. $2^{\circ}$ desta Lei (Brasil, 2001).

A Constituição Federal e o Estatuto da Cidade estabelecem também o Direito à Moradia no rol dos direitos sociais (a partir de 1996), e reconhecem o direito de posse, possibilitando a legalização dos assentamentos informais (Cardoso, 2011).

No PDPFor a Função Socioambiental da Propriedade está definida em seu art. 3o a partir da garantia de: i) justiça social; ii) direito à cidade; iii) proteção, preservação e valorização do patrimônio cultural, artístico, estético, histórico, turístico e paisagístico; iv) preservação e conservação do meio ambiente; e v) desenvolvimento sustentável. $\mathrm{E}$ define Direito à Cidade como "o direito à terra urbana, à moradia digna, ao saneamento ambiental, à infraestrutura urbana, ao transporte, aos serviços públicos, ao trabalho e ao lazer, para as presentes e futuras gerações" (Fortaleza, 2009).

Assim, o Direito à Cidade e o cumprimento da Função Social da Propriedade, conforme expressos no PDPFor se efetivam com a concretização do direito à moradia, à sustentabilidade e outros direitos, e para tanto precisam da regulamentação e implementação de instrumentos urbanísticos previstos pela lei, especialmente as ZEIS, que deveriam compensar um século de produção desigual do espaço urbano fortalezense.

\section{A formação da desigualdade socioespacial em Fortaleza no século XX}

Durante o século XX a produção do espaço urbano (Villaça, 2009; Harvey, 2005) de Fortaleza se deu protagonizada pela iniciativa privada, e conformou a estrutura urbana da cidade atual, marcada pela desigualdade socioespacial e pela segregação urbana. Segundo Villaça (2009) "a segregação é um processo necessário à dominação social, econômica e política por meio do espaço”, o que marca a disputa pela cidade.

As primeiras moradias improvisadas de Fortaleza datam de meados do século XIX, e estão representadas em textos que acompanham as plantas da cidade à época e outros relatos, e Margarida Andrade representou em plantas de reconstituição àquelas que acompanham esses documentos (Andrade, 2012). 
Em fins daquele século, Fortaleza tinha como principal atividade econômica o comércio, concentrado com algumas famílias. Aos poucos os excedentes dessa atividade passaram para a atividade rentista perceptível pelo fato de grande parte das casas à época serem de aluguel (Andrade, 2012) - e para a compra de terras, incluindo terras públicas como as de marinha, o que dá início à concentração fundiária e imobiliária de propriedade de poucas famílias, como a Gentil e a Gradvhol, por exemplo (Silva, 1999).

As atividades rentistas e de compra de terras no início do século XX afastaram, cada vez mais, a possibilidade de pessoas de baixa renda se concentrarem no núcleo principal da cidade, o que fez com que começassem a se formar assentamentos improvisados precários em seus arredores, como é o caso do Moura Brasil, "a mais antiga forma de pré-favelamento que a cidade conheceu" (Castro, 1982 apud Andrade, 2012, p. 164). A formação do mercado de terras e a consolidação da atividade rentista, aliados às intensas migrações do começo do século, iniciou o processo de segregação da cidade que foi sendo intensificado durante o restante do século.

A atividade rentista e o processo de mercantilização da terra ${ }^{4}$ durante boa parte do século XX não tiveram regulação, e o espaço urbano de Fortaleza foi sendo produzido e financiado de acordo com os interesses da iniciativa privada. Os investimentos em infraestrutura eram em grande parte privados, feitos pelos donos das terras, que os alocavam de acordo com os lugares onde faziam os loteamentos. A expansão urbana da cidade aconteceu, portanto, com pouco planejamento estatal até meados do século XX.

Incialmente os loteamentos ${ }^{5}$ foram acontecendo ao redor do centro da cidade, e aos poucos foram se expandindo radialmente, por vezes até um pouco distante da mancha urbana existente. A partir da década de 1960, eles foram se direcionando prioritariamente para a porção leste e sudeste da cidade (Figura 1), o que configurou em fins daquele século, a parte mais elitizada da cidade.

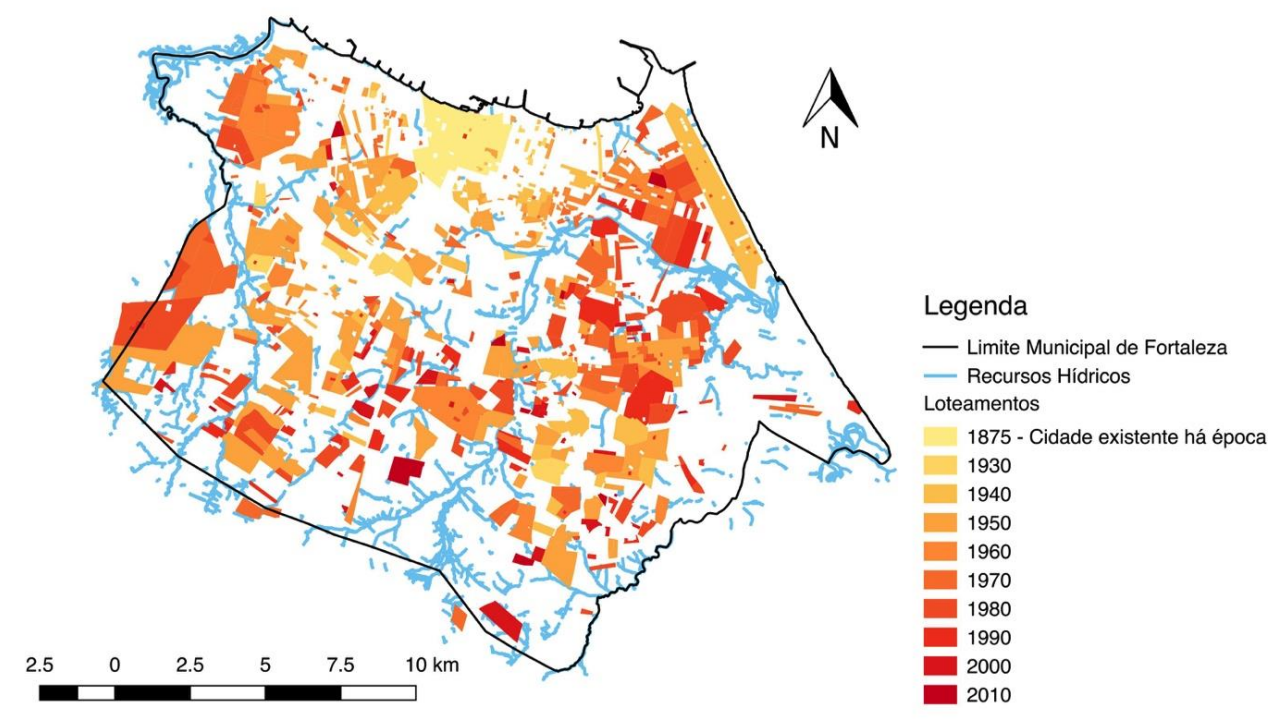

Figura 1 - Loteamentos aprovados pela Prefeitura de Fortaleza por década. Fonte: Dados da Secretaria de Finanças de Fortaleza (SEFIN) elaborado pela autora utilizando ferramenta QGis, 2020.

Os planos diretores do século XX não foram capazes de ordenar ou distribuir de forma equilibrada o crescimento urbano, que, consequentemente, aconteceu de acordo com os interesses da iniciativa privada e induzido por ela. Somente após a aprovação da Lei Federal de Parcelamento do Solo - Lei 6.766/79 houve a primeira regulamentação dos loteamentos, através da Lei Municipal no 5122.A/79 (Fortaleza, 1979).

\footnotetext{
4 Sobre o processo de mercantilização da terra no Brasil utilizou-se Martins (2010) e Smith (2008).

${ }^{5}$ Esses são os loteamentos aprovados pela Prefeitura e que possuem cadastro. Os primeiros registros são da década de 1930, e, portanto, a partir daí começam nossas análises. 0 material foi cedido pela Secretaria de Finanças de Fortaleza para a produção da tese (Brasil, 2016).
} 
As fortes secas que aconteceram no estado do Ceará nas décadas de 1950 e 1970 provocaram muitas migrações, que contribuíram para o crescimento populacional da cidade, e consequentemente para o aumento dos assentamentos irregulares, pois essas pessoas não conseguiam se inserir no mercado legal de terras. Esses assentamentos foram se formando às margens dos recursos hídricos, da linha do trem, próximo à praia, nas vias públicas, e em terrenos ociosos.

Frente a essa problemática habitacional, as décadas de 1960 e 1970 foram de grande produção estatal de habitação de interesse social (HIS), que seguiu a lógica da produção do Banco Nacional de Habitação (BNH) de periferização, com muitas unidades concentradas, falta de infraestrutura e falta de proximidade com o local de origem da população atendida (Figura 2) (Pequeno, 2008; Máximo, 2012).

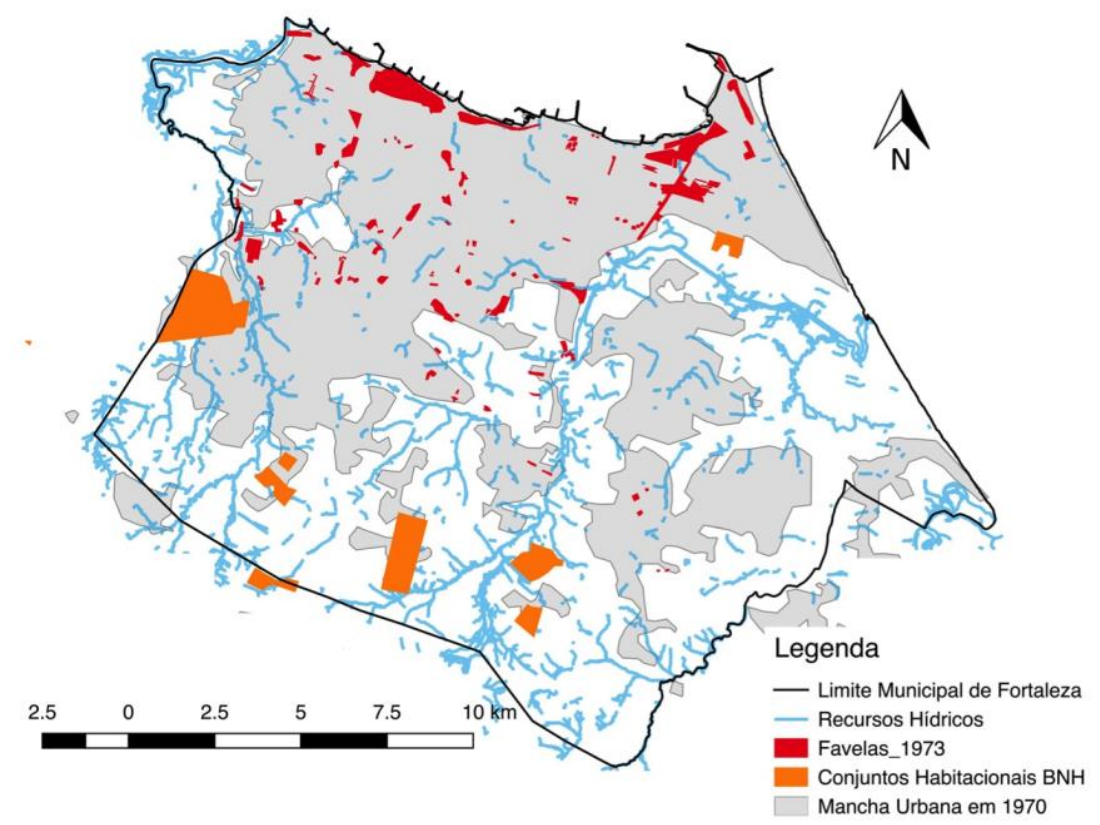

Figura 2 - Mancha Urbana na década de 1970 construída a partir dos loteamentos implementados até esta década, identificação das favelas em 1973 e conjuntos habitacionais construídos na década de 1970. Fonte: Dados dos loteamentos:

SEFIN / Dados das Favelas: PET-Arquitetura e Urbanismo UFC / elaborado pela autora utilizando ferramenta QGis, 2020.

Em 1992, após a promulgação da Constituição Federal, o Plano Diretor de Desenvolvimento Urbano de Fortaleza (PDDU-FOR) foi aprovado e precisou se adequar às exigências do capítulo da Política Urbana. 0 plano vigente até então era o Plano de Desenvolvimento Integrado da Região Metropolitana de Fortaleza (PLANDIRF), desenvolvido na década de 1970.

Na nova lei foram previstos alguns instrumentos urbanísticos, como: Regularização Fundiária; Solo Criado; Operação Urbana Consorciada (OUC); Parcelamento, Edificação e Utilização Compulsórios (PEUC); Contribuição de Melhoria; e Imposto Progressivo no Tempo, mas eles não foram implementados. 0 plano definiu a porção sudeste da cidade como Zona Adensável, consolidando a área de expansão a partir desse vetor e da localização da população de rendas médias altas e altas, que já se localizavam prioritariamente nessa direção (Fortaleza, 1992).

Dessa forma, ao fim do século XX Fortaleza estava consolidada de forma bastante segregada, marcada por uma concentração de população de rendas altas em sua porção leste e sudeste, concentração de população de baixa renda na porção oeste, e muitos assentamentos precários distribuídos pela cidade (Figura 3). 


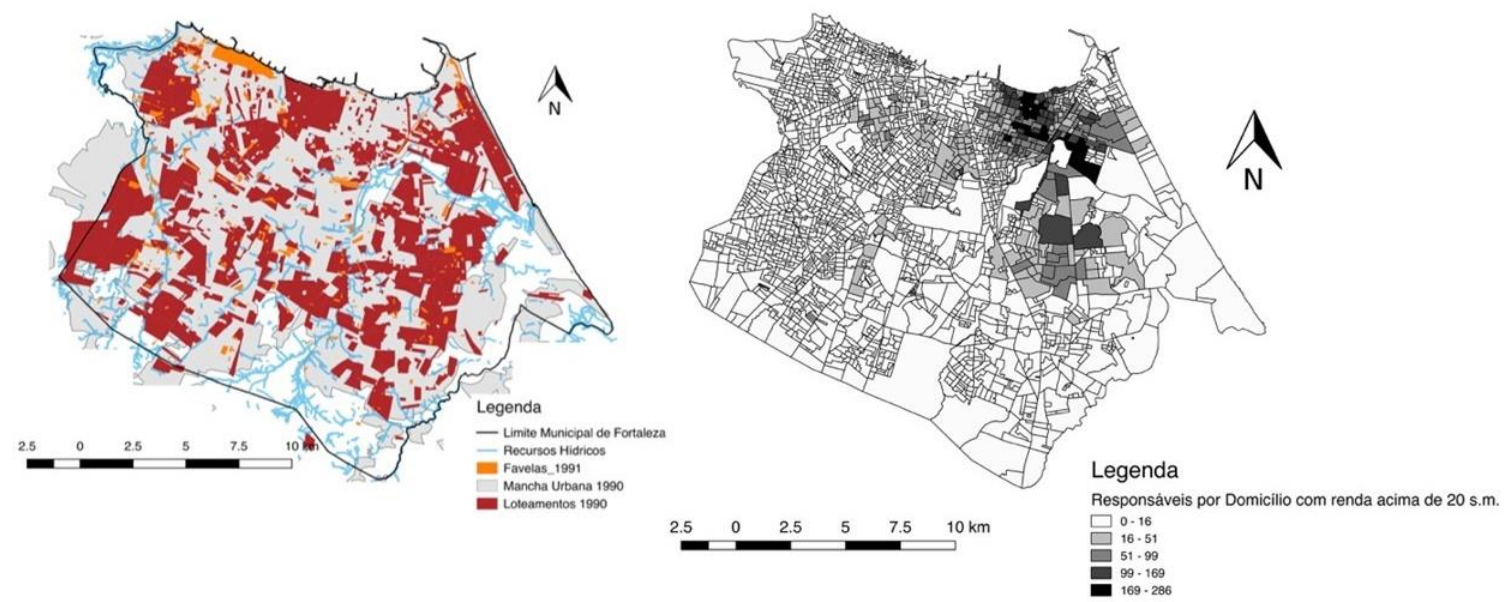

Figura 3 - Mapa à esquerda Mancha Urbana, Loteamentos e favelas em Fortaleza na década 1990. Fonte: Mancha Urbana e Favelas: PET - Arquitetura e Urbanismo UFC / Loteamentos: SEFIN / elaborado pela autora utilizando ferramenta QGis. Mapa à direita Setores Censitários com responsáveis por domicílio com renda acima de 20 s.m. (2000). Fonte: Dados do Censo IBGE 2000 elaborado pela autora utilizando ferramenta QGis.

\section{O Plano Diretor Participativo de Fortaleza: a construção e a desconstrução dos instrumentos urbanísticos}

O PDDU-FOR começou a ser revisto em 2002, quando completava 10 anos (conforme estabelece o Estatuto da Cidade), em um processo bastante conturbado. Em 2004, a partir de uma ação civil pública, o processo foi suspenso por falta de participação popular efetiva, por não conter o conteúdo mínimo exigido pela Constituição Federal e por fraude na licitação de contratação da empresa - $\operatorname{ASTEF}^{6}$ (Brasil, 2016).

Em 2005, em uma nova gestão da Prefeitura, o projeto de lei foi retirado da Câmara, e um novo processo de revisão foi iniciado em 2006, sob coordenação do Instituto Pólis. 0 tempo para elaboração do novo Plano Diretor era curto, o contrato previa 10 meses de trabalho.

Devido ao tempo reduzido, o processo foi apressado, e não houve tempo hábil para capacitação adequada da população para participação. Utilizou-se dos recortes espaciais já definidos para o Orçamento Participativo (OP) que dividia a cidade em 6 Áreas de Participação (AP) e já havia uma pré-organização. As etapas de elaboração foram então iniciadas com a capacitação, que se deu em forma de audiências públicas nas 6 AP e finalizadas com a entrega do projeto de lei para a Câmara. Além dessas, as etapas intermediárias incluíam: a leitura comunitária; o I Fórum do Plano Diretor - "A cidade que temos", em formato de audiência pública para receber contribuições da população; o II Fórum do Plano Diretor — "A cidade que queremos", onde seriam apresentadas e discutidas as propostas sistematizadas até o momento e seriam eleitos os delegados; e por fim o Congresso do Plano Diretor Participativo de Fortaleza (PDPFor) onde seriam pactuadas as propostas e elaborado o projeto de lei a ser enviado para Câmara de Municipal.

Devido à insuficiente preparação da sociedade civil, alguns grupos se organizaram e desenvolveram sua própria formação, destacando-se entre eles: a Universidade Federal do Ceará (UFC) - especialmente o curso de arquitetura e urbanismo - a rede $\mathrm{NUHAB}^{7}$, a Central dos Movimentos Populares (CMP) e algumas

\footnotetext{
${ }^{6}$ A Associação Técnico-Científica Engenheiro Paulo de Frontin é uma entidade jurídica de direito privado, vinculada ao Centro de Tecnologia da Universidade Federal do Ceará (http://www.astef.ufc.br).

7 A rede NUHAB (Núcleo de Habitação e Meio Ambiente) - filiada ao Fórum Nacional de Reforma Urbana (FNRU) - é formada por 12 organizações e movimentos sociais de Fortaleza: Federação de Bairros e Favelas de Fortaleza (FBFF); Movimento dos Conjuntos Habitacionais (MCH); Caritas Arquidiocesana de Fortaleza; Central dos Movimentos Populares (CMP); CEARAH Periferia; Centro Socorro Abreu; Escritório de Direitos Humanos e Assessoria Jurídica popular Frei Tito de Alencar; Centro de Assessoria Jurídica Universitária (CAJU-UFC); Núcleo de Assessoria Jurídica Comunitária (NAJUC-UFC); Serviço de Assessoria Jurídica Universitária (SAJU-Unifor); Oficina do Futuro e Centro de Defesa da Vida Herbert de Sousa (CDVHS) (Brasil, 2004 apud Brasil, 2016).
} 
comunidades. Essas organizações uniram-se em torno da temática habitacional, visto que não dariam conta de abordar uma grande diversidade de assuntos.

Assim, a partir dos conteúdos do plano, esses grupos centraram-se na defesa das Zonas Especiais de Interesse Social (ZEIS). Fizeram propostas para os assentamentos a serem reconhecidos, e identificaram terrenos vazios próximos a eles que pudessem ser definidos como áreas prioritárias para a construção de Habitação de Interesse Social (HIS). Essas propostas foram levadas para as audiências públicas e para o II Fórum do Plano Diretor.

A fase final do processo, antes de o projeto de lei ser enviado para a Câmara, foi o Congresso do PDPFor, que foi bastante tumultuado. A data de votação final foi adiada para 15 dias após o encerramento previsto, e não mais no último dia do evento. Além disso, 47\% dos delegados representavam o poder público, o que garantia vitória da votação sempre que necessária maioria.

A aprovação do PDPFor foi permeada de negociações, consequentes da disputa por interesses diversos. Segundo os movimentos sociais de luta pela moradia, houve ganhos e perdas ${ }^{8}$ para a conquista do Direito à Cidade e do cumprimento da Função Social da Propriedade.

A maioria das ZEIS, tanto de assentamento, quanto de vazio, propostas no início do Congresso foram acatadas. Mas algumas alterações consideráveis foram feitas: i) as de vazio do centro da cidade foram retiradas; ii) algumas áreas de vazios foram trocadas de bairros mais centrais e valorizados por outros menos valorizados e mais periféricos (Cavalcante et al.); e por fim, iii) a ZEIS de assentamento do Lagamar não foi aprovada.

Aconteceram perdas também em relação aos instrumentos de recuperação da mais-valia urbana, como por exemplo a Outorga Onerosa do Direito de Construir (OODC). Seis das nove zonas urbanas, dentre as áreas mais valorizadas da cidade, passaram a ter índice de aproveitamento máximo e básico iguais, o que inviabilizou o instrumento.

Os demais instrumentos não são autoaplicáveis, e não foram regulamentados diretamente no plano, sendo direcionados para legislação complementar específica, como: IPTU Progressivo, Contribuição de Melhoria etc. Não foram delimitadas as Operações Urbanas Consorciadas (OUC), nem as Zonas Especiais de Dinamização Econômica e Urbana (ZEDUS) ${ }^{9}$.

Alguns instrumentos, entretanto, que auxiliam na viabilização de transações imobiliárias foram regulamentados posteriormente à aprovação do PDPFor, como por exemplo: i) Outorga Onerosa de Alteração de Uso (OOAU); ii) Transferência do Direito de Construir (TDC); e iii) Regularização das edificações ${ }^{10}$.

As ZEIS, um dos mais importantes instrumentos de garantia do Direito à Cidade e do cumprimento da Função Social da Propriedade, também não foram regulamentadas no PDPFor, tendo sido indicadas para legislação específica, que não foi aprovada (até a data do estudo).

Foram estabelecidos 3 tipos de ZEIS:

Art. 126 - As Zonas Especiais de Interesse Social 1 (ZEIS 1) são compostas por assentamentos irregulares com ocupação desordenada, em áreas públicas ou particulares, constituídos por população de baixa renda, precários do ponto de vista urbanístico e habitacional, destinados à regularização fundiária, urbanística e ambiental.

Art. 129 - As Zonas Especiais de Interesse Social 2 (ZEIS 2) são compostas por loteamentos clandestinos ou irregulares e conjuntos habitacionais, públicos ou privados, que estejam parcialmente urbanizados, ocupados por população de baixa renda, destinados à regularização fundiária e urbanística.

\footnotetext{
${ }^{8}$ Algumas perdas aconteceram no Congresso do PDPFor, e outras na Câmara dos Vereadores, segundo os movimentos sociais de luta pela moradia entrevistados (Brasil, 2016).

${ }_{9}$ As ZEDUS foram regulamentadas e delimitadas em lei posterior - Lei de Parcelamento, Uso e Ocupação do Solo (LPUOS), Lei No 236/2017. Esse instrumento não foi analisado na tese. Para maiores detalhes sobre o instrumento ver: (Brasil, 2016).

${ }_{10}$ Esses instrumentos foram regulamentados pela Lei ํㅜ 10.335, de 1으 de abril de 2015.
} 
Art. 133 - ZEIS 3 - são compostas de áreas dotadas de infraestrutura, com concentração de terrenos não edificados ou imóveis subutilizados ou não utilizados, devendo ser destinadas à implementação de empreendimentos habitacionais de interesse social, bem como aos demais usos válidos para a Zona onde estiverem localizadas, a partir de elaboração de plano específico (Fortaleza, 2009, p. 16).

Ao todo foram delimitadas pelo PDPFor 134 ZEIS, mas posteriormente foi incluída a ZEIS Lagamar tipo 1 -, somando ao final 135, que se subdividem em: 45 do tipo 1 (34\%); 56 do tipo 2 (41\%); e 34 do tipo 3 (25\%). Elas estão distribuídas pelo território da cidade de maneira não homogênea, com concentração especialmente na periferia e porção oeste (Figura 4).

As ZEIS do tipo 2 foram definidas pois havia, na época, um programa para regularização dos conjuntos habitacionais existentes. Dessa forma, foram selecionados aqueles que seriam atendidos pelo programa, não havendo, portanto, grandes discussões com a população acerca de sua identificação e delimitação.

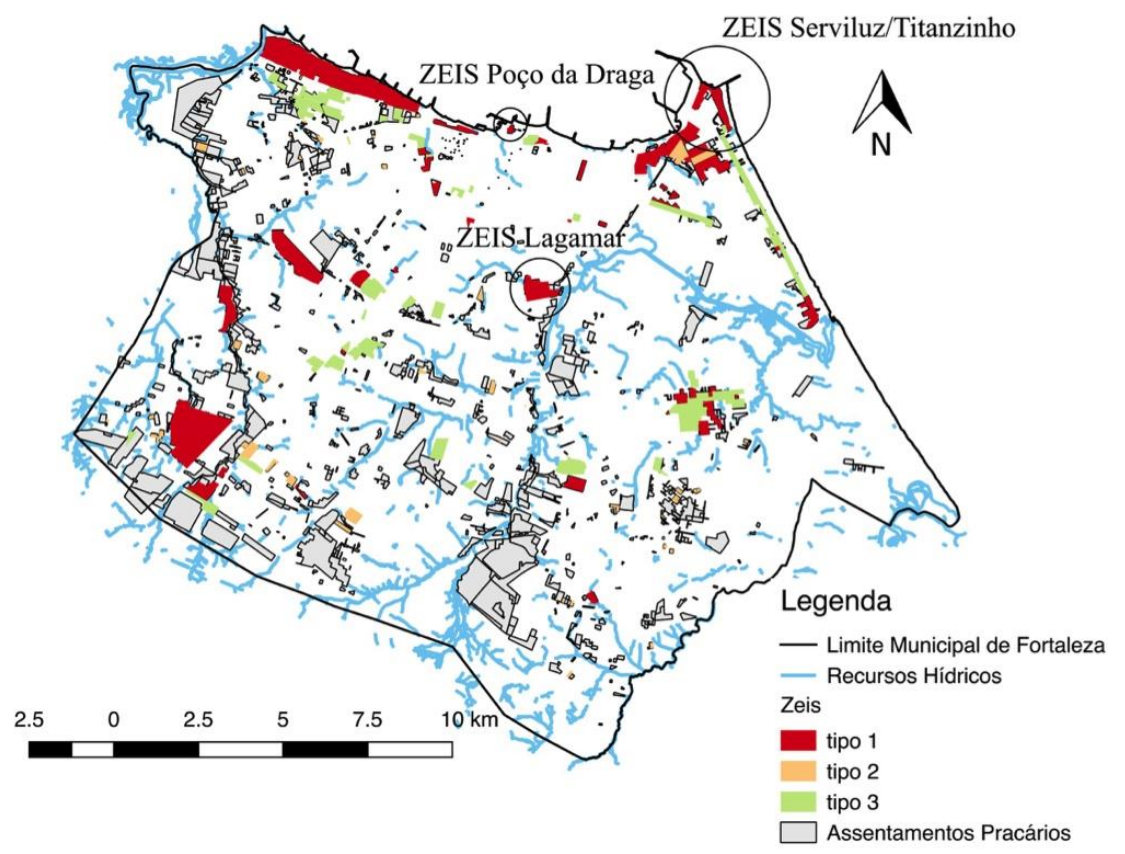

Figura 4 - ZEIS e Assentamentos Precários identificados pelo PDPFor. Fonte: Dados ZEIS: FORTALEZA, 2009 / Dados Assentamentos Precários: FORTALEZA, 2012 / elaborado pela autora utilizando a ferramenta QGis, 2020.

As ZEIS de vazio entraram em conflito direto com os interesses dos setores fundiário e imobiliário, pois destinavam terrenos vazios de determinadas áreas para construção de HIS. Por esse motivo, já sofreram modificações desde o Congresso do PDPFor, com a retirada de alguns perímetros mais valorizados e polêmicos. Posteriormente, ainda continuaram sofrendo modificações e perdas de áreas. Foi identificado, em 2015, que 4\% dos terrenos vazios internos às ZEIS 3 já haviam sido edificados pela iniciativa privada com autorização da Secretaria de Urbanismo e Meio Ambiente (SEUMA), desde a aprovação do PDPFor. E, que 10\% havia sido construído sem nenhuma autorização (Fortaleza, 2015). Há ainda uma pressão desses setores para que esse tipo de ZEIS deixe de existir, visto que não foi regulamentado.

As ZEIS do tipo 1 conflitam diretamente com a visão estratégica da cidade turística, pois há assentamentos precários consolidados em áreas de interesse dessa atividade. Esses conflitos foram, a nosso ver, essenciais para fazer com que a regulamentação desse tipo de ZEIS não acontecesse. Todavia alguns avanços são verificados, mas não têm sido suficientes para assegurar a permanência das comunidades no lugar de origem, mas principalmente, não tem garantido a melhoria urbana e habitacional dessas áreas. 
Neste artigo aprofundaremos os conflitos das ZEIS do tipo 1 e a cidade estratégica turística de Fortaleza ${ }^{11}$ a partir de três comunidades: Poço da Draga, Serviluz/Titanzinho e Lagamar (delimitadas na Figura 4).

\section{As ZEIS de Assentamento}

No PDPFor, para definição dos assentamentos precários, que seriam classificados como ZEIS tipo 1, foram consideradas algumas características (Brasil, 2016, p. 184-5):

$\begin{array}{ll}\text { 1. } & \text { Áreas sujeitas à especulação imobiliária } \\ \text { 2. } & \text { Carência de infraestrutura } \\ \text { 3. } & \text { Tempo de ocupação } \\ \text { 4. } & \text { Organização comunitária } \\ \text { 5. } & \text { Áreas homogêneas (tipologia das ocupações) } \\ \text { 6. } & \text { Vazios urbanos } \\ \text { 7. } & \text { Densidade populacional versus infraestrutura }\end{array}$

Entretanto, as ZEIS do tipo 1 não são representativas quando se considera o universo dos assentamentos precários (Figura 4). Os 45 polígonos são conformados por 101 assentamentos precários (12\%), e a cidade possui 843 (Fortaleza, 2015). A população que reside nas ZEIS é de 1.077 .000 pessoas, enquanto no total de assentamentos é de 2.450 .000 , o que representa somente $44 \%$.

Em termos espaciais, as ZEIS do tipo 1 somam $10,65 \mathrm{Km}^{2}$, ou seja, somente cerca de $3 \%$ da área de Fortaleza considerando a cidade como um todo, e esse território é ocupado por $15 \%$ da sua população.

Além de não serem representativas, as ZEIS não têm garantido à sua população a permanência no local onde estão situadas, e nem que, em caso de remoção necessária, seja reassentada dentro do perímetro, ou em suas proximidades.

A falta de garantia de reassentamento dentro do perímetro foi agravada em 2012, com a Lei Complementar No 0108, de 30 de maio, que retirou do regramento de ZEIS os terrenos e imóveis vazios quando localizados dentro do perímetro de uma do tipo 1. De acordo com o texto da lei:

Art. $1^{\circ}$ Fica acrescido ao art. 125 o $\S 4^{\circ}$, e os $\S 1^{\circ}$, com os incisos I e II, $2^{\circ}$ e $3^{\circ}$ ao art. 126 , todos da Lei Complementar $\mathrm{n}^{\circ}$ 0062, de 02 de fevereiro de 2009, que passam a vigorar com a seguinte redação:

(...)

"Art. 126

$\S 1^{\circ}$ São inválidas e sem eficácia como Áreas de Zona Especial de Interesse Social - 1 (ZEIS - 1) as áreas que, embora situadas dentro dos limites da ZEIS - 1, sejam constituídas de:

I - imóveis vazios, não utilizados pela população do assentamento irregular, desde que comprovada a regularidade da propriedade;

II - imóveis ocupados por qualquer atividade, que não sejam utilizados pela população do assentamento irregular, desde que comprovada a regularidade da ocupação.

$\S 2^{\circ}$ Aplica-se a esses terrenos de que trata o $\S 1^{\circ}$ a que dispõe a legislação urbana para a zona em que se situam as mesmos.

$\S 3^{\circ} 0$ enquadramento desses terrenos será feito pelos órgãos municipais competentes, quando solicitado pelo interessado, através de parecer técnico" (Fortaleza, 2012).

\footnotetext{
${ }^{11}$ A cidade de Fortaleza vem se consolidando como importante destino turístico, especialmente desde a década de 1990, tanto para lazer quanto para negócios. Esse projeto tem início com o Governo das Mudanças, governador Tasso Jereissati, e muitos investimentos foram feitos desde então para preparar a cidade (GONDIM, 2007). Recentemente foi aprovado o Plano Estratégico Fortaleza 2040 que expressa em seu texto as intenções para essa consolidação. Trabalha-se nesse artigo com visão de Planejamento Estratégico e Empresariamento dos autores Carlos Vainer (2007) e David Harvey (1996).
} 
Também não há uma relação entre a produção de conjuntos habitacionais e as ZEIS do tipo 3, que deveriam exercer essa função, localizando-se próximos das ZEIS tipo 1. Isso se dá devido a não regulamentação das ZEIS de vazio. A produção habitacional continua seguindo a lógica periférica.

As ZEIS do tipo 1 não foram regulamentadas, mas 3 delas tinham processo iniciado ${ }^{12}$ : Lagamar, Poço da Draga e Serviluz/Titanzinho. Duas delas estão localizadas na orla da cidade — Poço da Draga e Serviluz/Titanzinho, e a outra no caminho entre a orla - principal área turística - e o aeroporto e a Arena Castelão $0^{13}$ - Lagamar.

\section{Poço da Draga}

O Poço da Draga é uma comunidade localizada na orla da cidade: vizinho à Praia de Iracema, área tradicionalmente turística, onde teve início a construção do Acquário do Ceará ${ }^{14}$; próximo ao Centro Cultural Dragão do Mar de Arte e Cultura ${ }^{15}$; e vizinho à INACE - Industria Naval do Ceará empreendimento particular localizado no local onde existiu o primeiro porto da cidade (Figura 5).

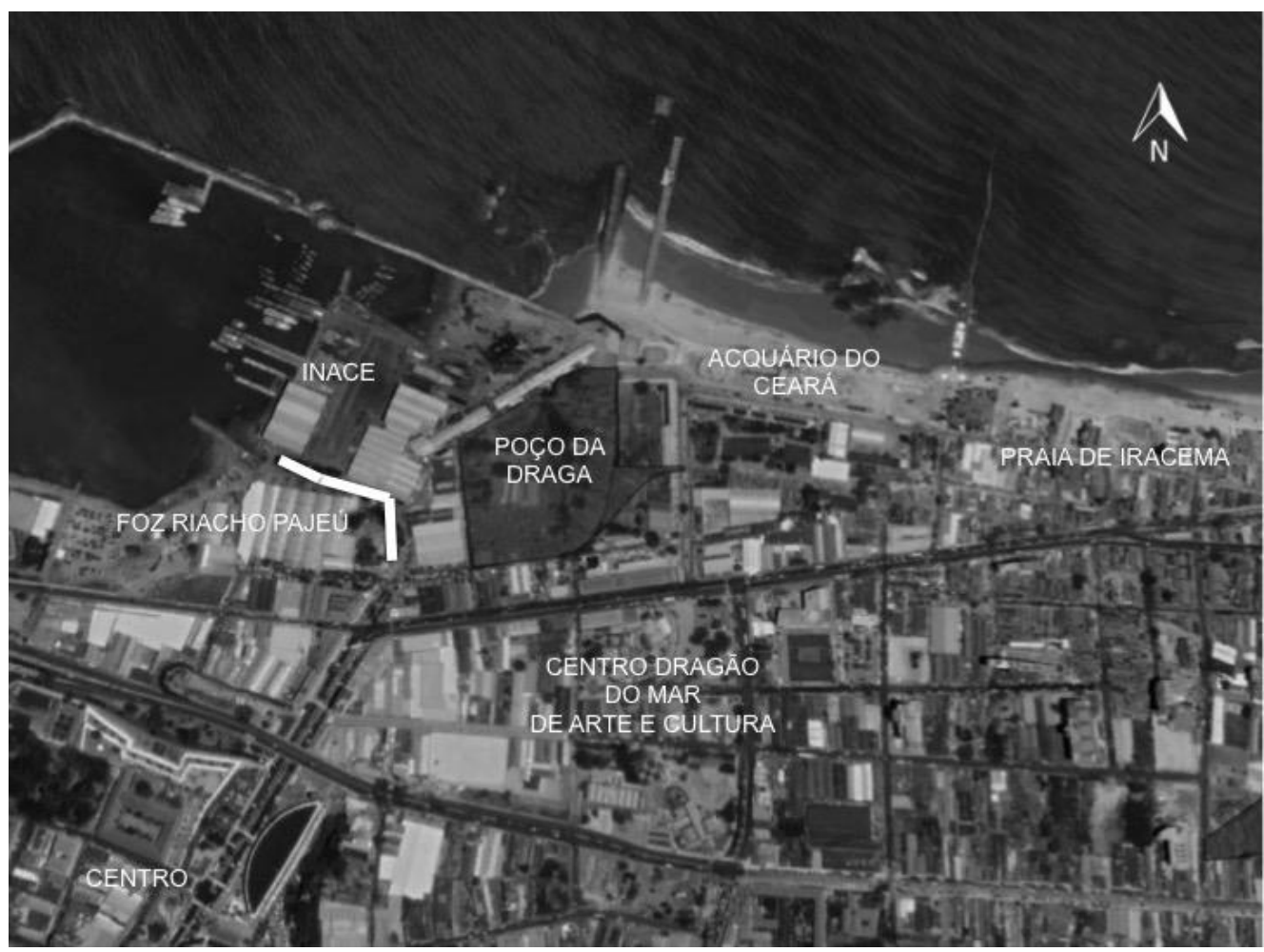

Figura 5 - ZEIS Poço da Draga e entorno. Fonte: Imagem Google Earth, elaborada pela autora.

O Poço da Draga é caracterizado predominantemente por população de baixas renda e escolaridade, e precariedade de infraestrutura urbana. Está localizado, segundo a prefeitura, em área de preservação permanente (APP) da foz do Riacho Pajeú, e por esse motivo, é considerado ocupando área de risco, e portanto vive ameaçada de remoção.

\footnotetext{
12 Esses processos haviam sido iniciados até a finalização da tese.

13 Antigo estádio de futebol Governador Plácido Aderaldo Castelo, ou Castelão, transformado em arena para os jogos da Copa do Mundo FIFA de Futebol de 2014.

14 O Acquário do Ceará é um empreendimento do Governo do Estado do Ceará, e seria o maior aquário da América Latina, estando com as obras paradas (Brasil, 2016).

15 Centro cultural construído pelo Governo do Estado do Ceará na década de 1990 em área de antigos galpões que davam suporte ao porto, quando este se localizava na Praia de Iracema, construído com o objetivo de requalificação urbana da área e ligaria o Centro à praia.
} 
Algumas propostas já foram feitas para retirada da comunidade daquele local, incluindo projetos de reassentamento em áreas próximas, o que não foi aceito pois as propostas não consideram seu modo de vida.

Não há relação de interação entre os equipamentos vizinhos e a comunidade, principalmente o Acquário, que nos mapas de divulgação não mostra a comunidade e indica o seu estacionamento na área dos galpões que o separam do Poço da Draga. Assim, apesar da boa localização, a comunidade está segregada da cidade que a envolve.

Apesar disso, existem entidades/organizações que apoiam os moradores e desenvolvem trabalhos coletivos com eles: LEC (Laboratório de Estudos da Cidade / UFC); Coletivo Flor de Urucum; ONG Velaumar; Movimento Quem Dera ser um Peixe dentre outros.

Nesses trabalhos coletivos a comunidade identificou não estar localizada na foz do Riacho Pajeú situada na verdade dentro do espaço da INACE. Assim sendo, não é uma área de risco sendo este um discurso para sua remoção. Segundo os moradores, a área às vezes fica empossada, mas devido à falta de um sistema de drenagem eficiente.

0 processo de regulamentação dessa ZEIS teve início em fins de 2012, quando os moradores começaram a ser mobilizados pela Prefeitura para as eleições do Conselho Gestor. Aconteceram algumas reuniões com os moradores para explicar o que era ZEIS, o que era o Conselho Gestor, como seria o processo de eleição etc. As reuniões foram acompanhadas por aquelas entidades/organizações apoiadoras.

Dia 08 de dezembro daquele ano foi marcada uma assembleia para definição dos candidatos a compor o Conselho Gestor, e no dia 09 aconteceu a eleição. A documentação foi encaminhada pela HABITAFOR (Fundação de Desenvolvimento Habitacional de Fortaleza) aos demais órgãos da Prefeitura. Entretanto, até o fim de 2012 o decreto de criação do Conselho não foi assinado pela Prefeita, e houve mudança de gestão. Até hoje a ZEIS não foi regulamentada.

\section{Serviluz/Titanzinho}

A ZEIS Serviluz/Titanzinho ${ }^{16}$ está localizada no extremo leste da cidade, próximo ao Porto do Mucuripe, parcialmente desativado após a construção do Porto do Pecém - São Gonçalo do Amarante (CE). As comunidades se formaram em dependência das atividades do porto, e hoje vivem principalmente de pequenos comércios e prestação de serviços, dentro e fora das comunidades. A população é de baixas renda e escolaridade, tem precariedade de infraestrutura, e, e a maior parte está localizada em faixa de praia.

Com a diminuição das atividades portuárias no local, e devido à grande potencialidade paisagística, projetos de requalificação da área começaram a ser propostos.

A área é conflituosa pois algumas atividades industriais e portuárias ainda estão em funcionamento, como a Petrobrás com seus tanques de estocagem de combustível e um porto que atende ao Moinho Dias Branco Indústria e Comércio de Alimentos. Também há uma porção sob controle da Capitania dos Portos e outras instituições, que é fechada de acesso ao Público (Figura 6).

Para a Copa do Mundo de Futebol da FIFA, foi instalado um terminal marítimo de passageiros na Praia Mansa. Esse terminal deveria ser ligado à Arena Castelão por um Veículo Leve sobre Trilhos (VLT), que iria aproveitar a linha do trem de cargas existente, antigo ramal de cargas Parangaba-Mucuripe. Entretanto, parte das margens do trilho está ocupada por moradias, que deveriam ser desapropriadas para instalação do VLT, relocando as famílias em terreno próximo à comunidade.

Além dessas, o último projeto previsto para essa orla - Aldeia da Praia —, que a adequaria para recepção dos turistas que chegassem de navio, também relocaria uma grande parte da comunidade para o mesmo terreno.

\footnotetext{
${ }^{16}$ A ZEIS Serviluz/Titanzinho é composta por dois polígonos, um que abrange a comunidade do Titanzinho e outro que abrange duas comunidades: a do Serviluz e o Casa do Samba. Entretanto, oficialmente para a Prefeitura essa área constitui uma única ZEIS, a do Serviluz/Titanzinho.
} 
O projeto Aldeia da Praia previa promover a ligação entre a Beira-Mar e a Praia do Futuro — porções do litoral que possuem infraestrutura para turistas - e para tanto requalificar parte das vias internas à comunidade. Além disso, o projeto previa melhoria habitacional, regularização fundiária e a construção de um Conjunto Habitacional com 1.000 unidades para atender a toda a população atingida por esse projeto e pelo do VLT. A comunidade do Titanzinho seria a mais atingida, com a retirada de todas as casas para construção de um calçadão, visto que a Prefeitura afirmava que ela estava localizada em área de risco, na faixa de praia.

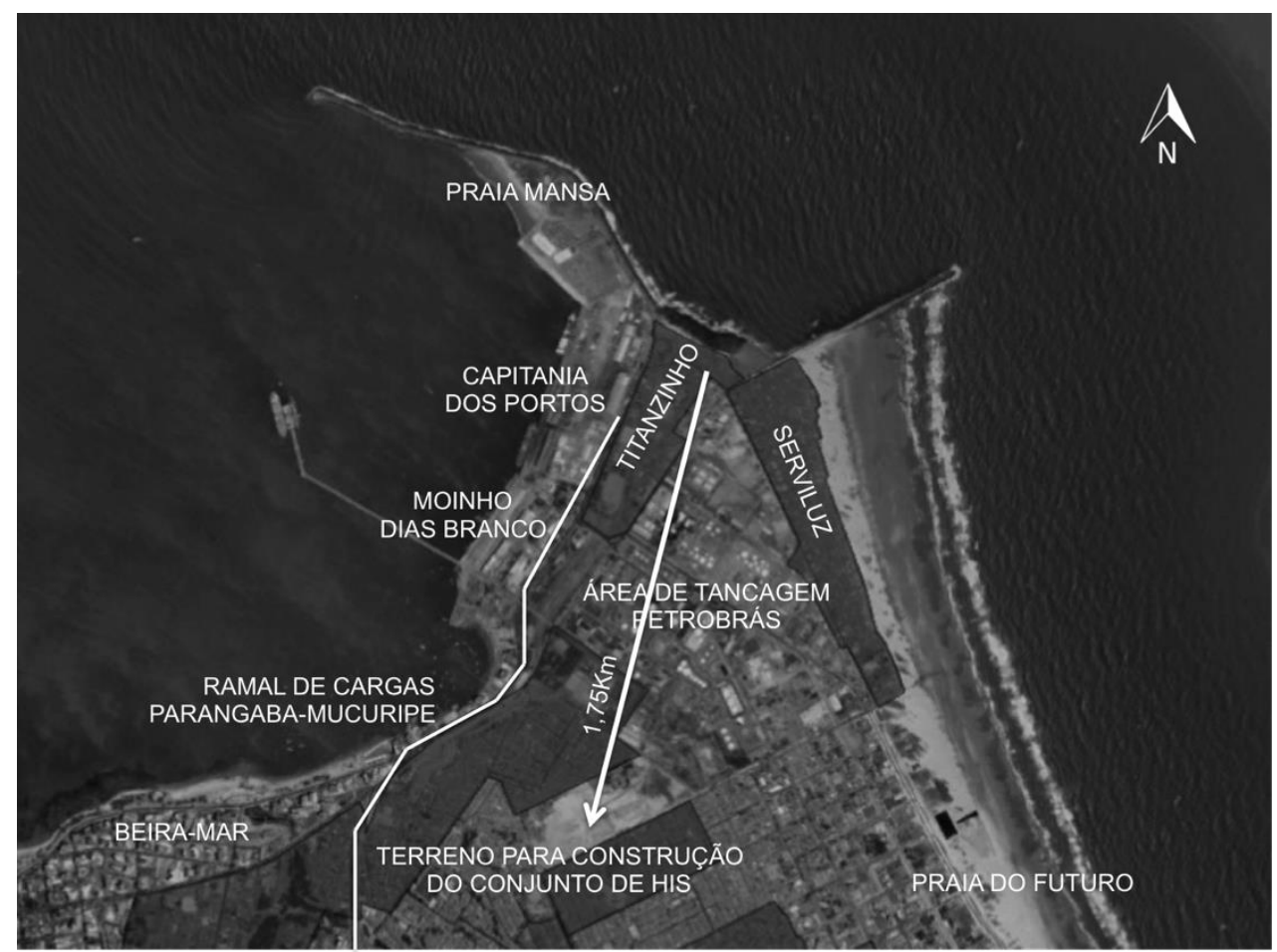

Figura 6 - ZEIS Serviluz/Titanzinho e entorno. Fonte: Imagem Google Earth, elaborada pela autora.

O terreno para onde a comunidade deveria ser removida está fora do perímetro da ZEIS, dista em linha reta $1,75 \mathrm{Km}$ dela (Figura 6) mas está localizado em cima do Morro Santa Terezinha, onde vive outra comunidade. Além disso, o terreno que estava livre à época da proposta foi ocupado por um grupo pertencente a um movimento de luta por moradia, e foi chamado de Alto da Paz. Essa comunidade foi brutalmente expulsa do local, e foi abrigada por outras comunidades vizinhas, incluindo Titanzinho e Serviluz.

Além dessas complicações, o terreno está localizado em uma Zona de Interesse Ambiental (ZIA), a da Praia do Futuro, e por isso sua permissividade de construção deveria ser baixa. Entretanto, houve uma adequação nos índices de construção, para que permitisse a proposta da Prefeitura.

Após os conflitos com a comunidade Alto da Paz foram feitas mudanças no projeto e o novo conjunto habitacional proposto prevê 1.472 unidades, em um terreno de $6.000 \mathrm{~m}^{2}$, compostos por 92 blocos de 16 apartamentos cada. Parte dessas unidades, cerca de 300, atenderão à comunidade Alto da Paz. A tipologia é padronizada e repetitiva. As obras não tiveram início até então e o conflito não foi ainda resolvido.

A comunidade tem importante relação com o mar, tanto de trabalho quanto de lazer e projetos sociais, e acreditava que sua transformação em ZEIS garantira a permanência no local. Solicitou, portanto, à Prefeitura a sua regulamentação. Representantes da HABITAFOR estiveram na comunidade, e em 2011 começaram as reuniões para preparar as eleições do Conselho Gestor, mas o processo foi interrompido sem maiores esclarecimentos. A ZEIS não está regulamentada até hoje, e continua ameaçada de deixar o local. 


\section{Lagamar}

A ZEIS Lagamar não foi incluída no PDP-FOR quando da sua aprovação. A justificativa da Prefeitura é que eles não participaram do processo de elaboração do plano. A comunidade, entretanto, discorda do argumento, e afirma que não foram transformados em ZEIS, pois estão localizados em área estratégica entre a Beira-Mar e o Aeroporto e a Arena Castelão.

Após mobilização e luta da comunidade, em 2010 o Lagamar foi finalmente transformado em ZEIS do tipo 1, através da Lei Complementar № 0076.

Estão situados aproximadamente no centro geográfico da cidade. São caracterizados por uma população de baixa renda e escolaridade e precariedade de infraestrutura. Parte da comunidade está situada às margens do canal do Lagamar, afluente do Rio Cocó, e têm este rio como limite à leste, fazendo com que sofra com alagamentos em períodos chuvosos. A linha de trem de cargas Parangaba-Mucuripe corta a comunidade (Figura 7), e atualmente a linha do VLT.

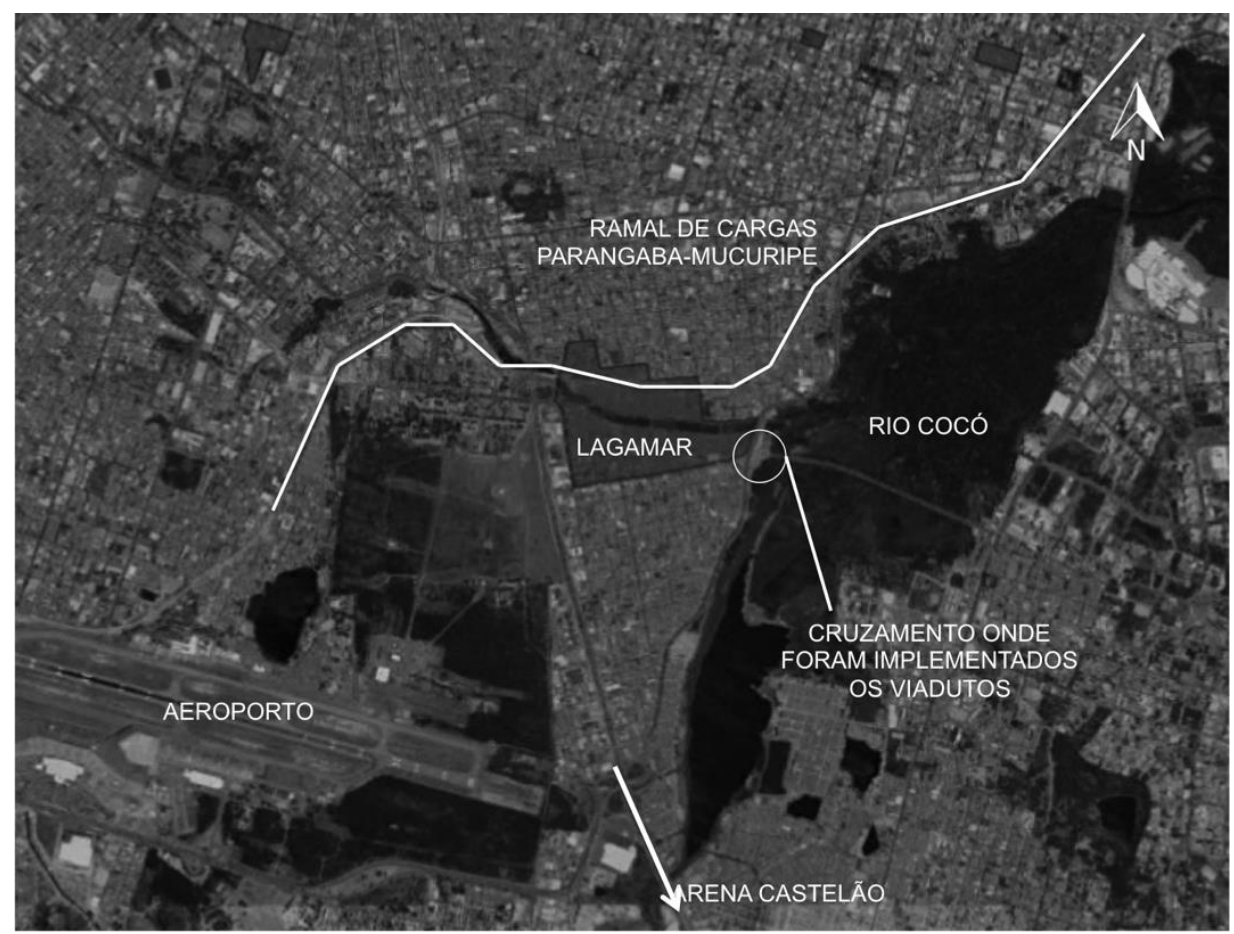

Figura 7 - Localização da ZEIS Lagamar. Fonte: Imagem Google Earth, elaborada pela autora.

Para os moradores a conquista da transformação em ZEIS garantiria a permanência da comunidade no local onde estão, mas a ZEIS não foi regulamentada até hoje. O Lagamar foi a ZEIS que mais avançou no processo, mas não chegou a finalizar. 0 Conselho Gestor foi eleito e se reuniu algumas vezes. 0 Conselho é paritário entre membros da Prefeitura e dos moradores, mas o presidente é representante da Prefeitura, o que faz com que em todas as decisões que precisem de maioria, as preferências do poder público sejam atendidas.

Apesar do Conselho Gestor, não foi desenvolvido o Plano de Regularização Fundiária e Urbanística para a comunidade, conforme estabelece o PDPFor.

Mesmo com o Conselho Gestor instaurado, parte da comunidade foi retirada para a construção de duas obras viárias estratégicas: o VLT - no local do ramal de cargas - e um conjunto de viadutos com rotatória em um importante cruzamento contíguo à comunidade.

O VLT faria a ligação entre o terminal de passageiros do Mucuripe e a Arena Castelão, aproveitando o ramal de cargas existente, conforme comentado. Entretanto, como as margens desse ramal estão ocupadas por moradias e a implementação do VLT necessitaria de um espaço maior do que o ramal de cargas, seria preciso desapropriar muitas edificações. A extensão do ramal é longa e perpassa por várias comunidades, 
mas não houve uma negociação conjunta entre todos os atingidos. 0 Governo do Estado do Ceará negociou caso a caso.

Parte dessas moradias está situada dentro da ZEIS Lagamar, e precisavam ser retiradas para que as obras começassem. 0 processo de negociação, entretanto, foi muito tumultuado, visto que a quantidade de casas atingidas inicialmente era muito grande. Aconteceram algumas reuniões com os moradores e lideranças. Foi contratada uma empresa para fazer o trabalho social. Após muitas discussões e algumas mudanças no projeto, ficou acertado que haveriam 3 opções, a serem decididas individualmente por família atingida: i) ser relocada para um conjunto habitacional que estava sendo construído no bairro José Walter ${ }^{17}$; ii) receber indenização e procurar nova moradia; e ainda iii) aguardar, em aluguel social, a construção de pequenos conjuntos habitacionais em terrenos próximos à comunidade que o Governo do Estado do Ceará ainda tentaria adquirir com os proprietários. Houve famílias que escolheram cada uma das opções.

As famílias que quiseram ir para o Cidade Jardim já estão lá. Uma parte foi indenizada e saiu da comunidade. As que recebem aluguel social, entretanto, não conseguiram alugar outra casa dentro da comunidade, devido à grande valorização imobiliária com o início desse processo, e foram para longe, ou estão na casa de parentes/amigos, ou alugaram quartos em casas de outras famílias, aumentando a precariedade habitacional. Os terrenos próximos não foram adquiridos e os conjuntos não iniciaram as obras.

As casas vazias foram derrubadas e os escombros demoraram a ser retirados para evitar que fossem construídas novas no lugar. A morosidade foi prejudicial para os moradores, pois a sujeira e os entulhos acumularam bichos, insetos, provocando doenças. As obras do VLT ficaram prontas, e esse trecho está em funcionamento, dividindo a comunidade ao meio.

0 projeto dos viadutos também sofreu muitas modificações após negociações com a comunidade, reduzindo consideravelmente a quantidade de casas atingidas, de 71 para 11, incluindo 18 famílias e alguns comércios (Brasil, 2016). Para essas famílias não foi dada a opção de relocação, somente as indenizações foram negociadas caso a caso. A obra está finalizada e, além de afetar a comunidade, o conjunto atingiu também parte da APP do Rio Cocó.

Nenhuma das propostas foi discutida na instância do Conselho Gestor da ZEIS. Cada uma foi discutida individualmente com cada família, ou com pequenos grupos organizados pela própria comunidade.

Percebe-se que, apesar da existência do Conselho Gestor - no caso do Lagamar — e do início do processo de regulamentação - nesse e nos demais casos - o instrumento ZEIS não foi capaz de garantir a permanência de toda a população no local, dependendo sempre da luta individual e contínua dos moradores. Parte das comunidades não conseguiu resistir à pressão dos investimentos da Prefeitura e do Governo do Estado. Nenhuma delas recebeu melhorias, ou foi iniciado programa de regularização fundiária. 0 fato de terem sido transformadas em ZEIS não alterou a dinâmica dos moradores.

\section{Considerações Finais: Instrumentos Urbanísticos para quem?}

Apesar do cenário concreto de pouca garantia dos direitos das ZEIS, mesmo passados anos de aprovação do Plano Diretor Participativo de Fortaleza, alguns avanços aconteceram de forma lenta, mas são importantes de serem destacados.

Em 2011, sob pressão popular, através do Decreto Municipal no 13.241, de 21 de outubro de 2013, a Prefeitura criou o Comitê Técnico Intersetorial e Comunitário das ZEIS, que tem como objetivo "subsidiar o Executivo Municipal de informações suficientes para tomada de decisão relativamente à regulamentação e à implementação das zonas especiais de interesse social (ZEIS) no âmbito do território municipal" (IPLANFOR, 2016). 0 comitê é composto por 29 membros, sendo 17 representantes do poder público

17 O Conjunto Habitacional Cidade Jardim foi construído no bairro José Walter, periférico de Fortaleza, distando 8Km da comunidade, e foi viabilizado pelo Programa Minha Casa Minha Vida. O bairro já abriga outro grande conjunto habitacional construído no período BNH que deu origem ao bairro e possui o mesmo nome. Quando finalizado terá mais de 5.000 UH, e receberá famílias de várias comunidades diferentes da cidade, atingidas por outros projetos. 
municipal e o restante da sociedade civil com participantes de 9 ZEIS, consideradas prioritárias: Lagamar, Pirambu, Poço da Draga, Praia do Futuro, Moura Brasil, Mucuripe, Serviluz, Pici e Bom Jardim.

Esse Comitê, entretanto, não começou a trabalhar imediatamente, e somente no dia 26 de outubro de 2015, em solenidade no Paço Municipal, entregou ao Prefeito um relatório com a situação geral das ZEIS do tipo 1 e do tipo 3 e proposições importantes para dar continuidade à regulamentação do instrumento.

No mesmo dia da entrega do relatório, o Prefeito assinou um decreto criando a "Comissão de Proposição e Acompanhamento da Regulamentação das Zonas Especiais de Interesse Social (ZEIS)”. A assinatura, entretanto, foi simbólica, e o decreto só foi publicado no Diário Oficial em 01 de julho de 2016, o que daria a permissão para o início dos trabalhos. A primeira reunião só aconteceu em 20 de julho do mesmo ano.

Em 2019 a Prefeitura começou o processo de regulamentação das ZEIS prioritárias, dando início aos seus Planos Integrados de Regularização Fundiária (PIRF). Cada PIRF está sendo desenvolvido por uma equipe diferente, externa à Prefeitura, algumas coordenadas pelas Universidades (Universidade Federal do Ceará - UFC, Universidade Estadual do Ceará — UECE e Universidade de Fortaleza — UNIFOR).

0 principal entrave à regulamentação das ZEIS em Fortaleza é a falta de diálogo entre a política urbana, os projetos estratégicos da cidade turística, e os interesses dos setores imobiliários. Em paralelo a todo esse processo foi desenvolvido o plano estratégico Fortaleza 2040, que não dialogou com o PDPFor, nem com o processo de regulamentação das ZEIS, nem com a revisão da Lei de Parcelamento, Uso e Ocupação do Solo (LPUOS). A revisão da LPUOS aconteceu independente da regulamentação dos instrumentos urbanísticos e foi, por vezes, de encontro aos objetivos e diretrizes do PDPFor. Dentre algumas divergências, a lei promove a regulamentação das ZEDUS, ampliando as quantidades e delimitações (Brasil, 2016).

Outro entrave à regulamentação das ZEIS é a propriedade privada da terra junto a não implementação dos instrumentos de cumprimento da função social da propriedade e regularização fundiária. Para que aconteçam avanços é necessário que esses instrumentos sejam regulamentados e implementados, e que sejam trabalhados juntos às políticas urbanas e habitacionais.

É necessário também que sejam criados mecanismos de controle social da política urbana efetivos, para que a cidade seja pensada, integrada e para todos. Entretanto, atualmente o que tem acontecido é a desconstrução dos mecanismos existentes.

Por fim, outro importante entrave é a lógica de produção do espaço segregacionista, resultado de uma visão neoliberal e patrimonialista. Durante o século XX o espaço urbano nas grandes cidades brasileiras, também em Fortaleza, se deu privilegiando uma pequena parcela da população em detrimento da maioria. Apesar do contexto neoliberal, seria possível lidar de forma diferente com o planejamento e a gestão do solo, garantindo mistura social 18 e democratização do espaço urbano através dos instrumentos urbanísticos.

Além dos entraves, o instrumento tem um importante desafio: a continuidade da garantia do Direito à Cidade após sua efetivação. Na cidade de Fortaleza, até hoje, a cidade estratégica e os direitos de propriedade advindos da mercantilização da terra urbana têm prevalecido sobre os direitos das comunidades tradicionais, mesmo as reconhecidas como ZEIS.

\section{Referências}

Andrade, M. J. F. S. (2012). Fortaleza em perspectiva histórica: poder público e iniciativa privada na apropriação e produção material da cidade 1810-1933 (Tese de Doutorado). Faculdade de Arquitetura e Urbanismo, Universidade de São Paulo, São Paulo.

Brasil, A. (2016). A ineficácia das ZEIS: um problema de legislação ou uma questão político-social? - O caso de Fortaleza (Tese de doutorado). Faculdade de Arquitetura e Urbanismo, Universidade de São Paulo, São Paulo.

\footnotetext{
18 Na tese foi estudado o caso da França, em especial de Paris, da produção e gestão do espaço com a tentativa de promoção da mistura social (mixté sociale). Ver: (BRASIL, 2016), cap. 3, p. 82-129.
} 
Brasil, A., Cavalcanti, E., \& Capasso, M. (2017). A mercantilização do espaço urbano em Fortaleza: instrumentos urbanísticos como meio de promoção de negócios imobiliários em detrimento da democratização do espaço urbano. In Anais do XVII Encontro Nacional da ANPUR. São Paulo: ANPUR.

Brasil, A., Serpa, J., Oliveira, L., Campos, M., \& Silveira, M., Rabelo, P., Pedrosa, R., \& Vieira, S. (2016). Zonas especiais de interesse social em fortaleza: progressos, retrocessos e hipóteses do que deveria ter avançado para sua regulamentação. In Anais do II SEMINARIO NACIONAL SOBRE URBANIZAÇÃO DE FAVELAS. Rio de Janeiro: UrbFavelas.

Cardoso, A. L. (2011). Direito à cidade e o direito à moradia: do fim do BNH ao governo Lula. In Santos JR., O. A. dos (org.). Políticas públicas e direito à cidade: programa interdisciplinar de formação de agentes sociais e conselheiros municipais. Rio de Janeiro: Letra Capital: Observatório das Metrópoles: IPPUR/UFRJ.

Cavalcante, F., Frota, N., \& Furtado, L. (2012). ZEIS em Fortaleza: a insustentabilidade do instrumento diante das pressões exercidas pelo mercado imobiliário. In Anais do $2^{\circ}$ Congresso Internacional Sustentabilidade e Habitação De Interesse Social. Porto Alegre.

Fortaleza. Instituto de Planejamento de Fortaleza. (1992). Plano Diretor de Desenvolvimento Urbano. Fortaleza.

Fortaleza. Secretaria de Urbanismo e Meio Ambiente (SEUMA). (2009). Plano Diretor Participativo. Fortaleza.

Fortaleza. Secretaria de Urbanismo e Meio Ambiente (SEUMA). (2012). Lei Complementar no 0108. Fortaleza.

Fortaleza. Instituto de Planejamento de Fortaleza (IPLANFOR). (2015). Relatório das ZEIS. Fortaleza.

Gondim, L. M. P. (2007) O Dragão do Mar e a Fortaleza Pós-moderna. São Paulo: Annablume.

Harvey, D. (1996). Do gerenciamento ao empresariamento: a transformação da administração urbana no capitalismo tardio. Espaço e Debates, 39, 48-64.

Harvey, D. (2005). A produção capitalista do espaço. São Paulo: Annablume.

Harvey, D. (2014). Cidades rebeldes: do Direito à cidade à Revolução Urbana. São Paulo: Martins Fontes.

Instituto de Planejamento de Fortaleza - IPLANFOR. Iplanfor. (2016). Comitê das ZEIS. Fortaleza: IPLANFOR. Recuperado em 08 de janeiro de 2016, de http://www.fortaleza.ce.gov.br/iplanfor/comite-das-zeis.

Lefebvre, H. (2004). O Direito à Cidade (3 $3^{\mathrm{a}}$ ed.). São Paulo: Centauro.

Martins, J. S. (2010). O cativeiro da terra. São Paulo: Contexto.

Maximo, F. R. C. C. (2012). Moradia, arquitetura e cidade: mudanças e permanências na produção da habitação social no espaço urbano metropolitano de Fortaleza (Dissertação de Mestrado). Instituto de Arquitetura e Urbanismo, Universidade de São Carlos, São Carlos.

Pequeno, L. R. B. (2008) Políticas Habitacionais, Favelização e Desigualdades Sócio-Espaciais nas Cidades Brasileiras: Transformações e Tendências. In Anais do X Colóquio Internacional de Geocrítica. Barcelona.

Silva, A. C. M. (1999). A propriedade privada da terra e a produção de novas espacialidades na cidade de Fortaleza (Tese de Doutorado). Faculdade de Filosofia Letras e Ciências Humanas, Universidade de São Paulo, São Paulo.

Smith, R. Propriedade da terra e transição: estudo da formação da propriedade privada da terra e transição para o capitalismo no Brasil. São Paulo: Brasiliense, 2008.

Vainer, C. B. (2007). Pátria, empresa e mercadoria. Notas sobre a estratégia discursiva do Planejamento Estratégico Urbano. In Arantes, O., VAINER, C., \& Maricato, E. A cidade do pensamento único: desmanchando consensos. 4⿳ạ. ed. Petrópolis: Vozes.

Villaça, F. (2009). Espaço intra-urbano no Brasil. São Paulo: FAPESP / Studio Nobel.

Editor: Rodrigo Firmino

Recebido: 21 set. 2020

Aprovado: 18 jan. 2021 